might drink them with equal effect at Hampstead or Croydon by an outlay of a few pence. With a view to lessen the tide of folly whioh has so long overflowed the "pump rooms," and in order to discover an agreeable and harmless aperient for those refined palates and injudicious heads, which may be disposed to appeal from the science and discretion of a regular practitioner, to the quackery and humbug of mineral spas, we have carefully examined "Laming's Tasteless Cheltenham Salts," both as to their chemical and medicinal relations, and we may observe with much satisfaction, that the solution formed by them while in a state of effervescence, is particularly agreeable to the taste, and also highly efficacious as an aperient. It is not a patent medicine, it is not a quack medicine, and Mr. Laming, we believe, pretends to no secret method of preparation. At all events we are no encouragers of secrets in matters that are calculated to mitigate the sufferings of mankind, and therefore we have no hesitation in saying, that by the appropriate reagents, we find in the solution, sulphate of soda, iartrate of soda, tartrate of potash, and supercarbonate of iron. From this proximate analysis, the therapeutic value of the preparation may be readily estimated. On reference to eny standard analysis, it will be seen that Laming's salt differs from the true Cheltenham, in containing no muriate of magnesia, and in other particulars of less consequence. This defect, however, is counterbalanced by the substitution of tartrates, and the consequent absence of the disagreeable taste which the muriate of mag. nesia would unavoidably occasion.

\section{LONDON UNIVERSITY.}

\section{To the Editor of THE LANCET.}

Sin,-Lest it should appear that there is any want of honesty and openness in my conduct, I beg you to state, unequivocally, that I furnished you with the pamphlet relating to Mr. Grauville Sharp Pattison. Do, I entreat you, make every effort to let this notice be published with the "Correspondence ;" by doing which, you will materially oblige your obedient servant,

University Dispensary. Alex. Tromson, M.B.

[This note reached us too late to be inserted in the body of our last Number. ED. L.]
FRENCH MEDICAL STUDENTS.

Just as our Number was going to'press, we received the following letter. We beo to express our unqualified approbation of the suggestion it contains; for, surely, too much respect cannot be shown to the noble. minded and intrepid Parisian students, who, although undisciplined, so valiantly fought, bled, and conquered, in the cause of liberty. The meeting ought to be held in a medical theatre-the largest that can be found, and the Council of the London University would feel pleasure, we should think, in lending their Theatre of Anatomy for the praisewortlly purpose. With regard to the time, it had better be delayed, probably until the first week in October, when our medical pupils will have returned to the hospitals and class-rooms. It is a meeting at which every English student should be present.

\section{To the Editor of $\mathrm{T}_{\mathrm{H}} \mathrm{L}$ Lancer.}

SrR,-Considering the spirit of confraternity which unites the liberal medical men of this country to those of France, and the generosity with which the institutions of the French are thrown open to men of all nations ; considering, too, that the School of Medieine, as well as the Ecole Poly. technique and the Beole de Droit, have ever been in the foremost rank, despite of every kind of persecution, in the defence of freedom and justice; it seems to me that some particular expression of our admira. tion is due to the gallant children of scienee, for their conduct in the late hard struggle between liberty and despotism.

I have more than once stood with them against pointed bayonets, and the applause showered down on the laurels $[$ wou on the field of science, have made me well $a c$. quainted with their noble nature.

The gentlemen who have done me the honour to attend my lectures in Aldersgate Street, I am proud to say, participate in my sentiments, and will all come forward.

The only question is (you can best ansser it), When, where, and how , shall a meetrgg take place?

\section{T. Krivo \\ Un Ancien Interne de l'Hotel Dien,} and Lecturer on Anatomy aud Surger?.

10, Hanover St., Hanover Sq., Aug 1. 